\title{
In Retrospect: Leibniz's Protogaea
}

\author{
The first English translation of Gottfried Leibniz's earth science treatise records the difficulties of \\ understanding our planet before geologists appreciated deep time, Richard Fortey discovers.
}

\author{
Protogaea \\ by Gottfreid Wilhelm Leibniz \\ Translated by Claudine Cohen and \\ Andre Wakefield \\ University of Chicago Press: 2008. \\ 204 pp. $\$ 55$.
}

It is something of a game among historians to try and detect the earliest hints of a major scientific breakthrough in a little-known work discovered through recondite scholarship. Charles Darwin's supposed debt to his grandfather Erasmus is an example, or maybe geologist Charles Lyell's insufficient acknowledgement of the early geological work of Nicolaus Steno. When the savant in question is Gottfried Wilhelm Leibniz (1646-1716) - the man who developed calculus independently of Isaac Newton - hidden insights might genuinely be anticipated. Here was a prolific thinker of range and profundity. His Protogaea, a posthumously published 1749 treatise on earth sciences, has now been translated from its original Latin into English for the first time, and bears a title that chimes with our current concerns about global ecosystems. What did the great man make of the history of Earth?

As he states in the book, Leibniz intended to develop "the seeds of a new science called natural geography”. The original text would have been readily comprehensible to his contemporaries, and must surely have seeped into subsequent thoughts about geology. Indeed, had his book been a more complete account, 'geology' might have been a stillborn term.

As it is, Leibniz picks out facts derived from his own observations, from his network of correspondence with other natural philosophers, and from his wide reading of those he regards as trustworthy observers. His text briefly touches on many geological phenomena, from the formation of mountains to the origin of minerals and particularly fossils, which in this new translation are well illustrated by reproductions of the original contemporary woodcuts. Leibniz was unusually scathing for his time about those who 'see' miraculous religious resemblances in natural objects, and wrote: "credulity fills in the rough outlines shaped by accident". Richard Dawkins could not have put it better.

Presciently, Leibniz is equally clear about the organic nature of many fossils: fish preserved in slates are exactly that and not mere 'games

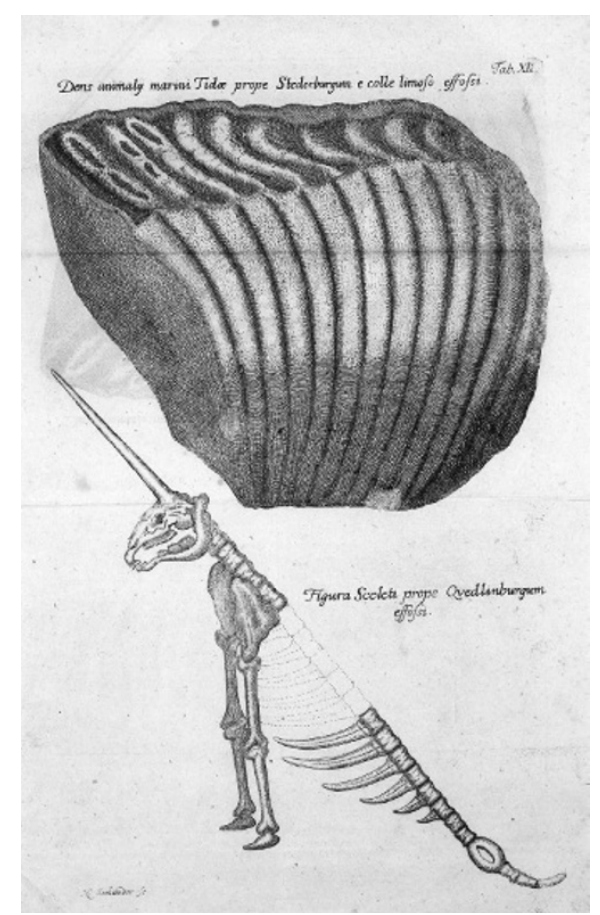

The 'unicorn' of Quedlinburg fooled even Leibniz.

of nature. He was reacting against philosophers such as Athanasius Kircher, who "claim the great architect, as if in jest, had imitated the teeth and bones of animals, shells or snakes". Leibniz was certain that God had much more serious purposes than planting simulacra in the rocks. Glossopetrae, or 'tongue stones', are shark's teeth, he states, nothing more or less. He recognizes ammonites and other fossil shells as having more than a passing similarity to their living relatives. The philosophical mind at work in these passages is of a modern, sceptical cast, highlighting that Leibniz was well ahead of most of his contemporaries.

Even Leibniz is occasionally credulous. One illustration in the book shows the unicorn of Quedlinburg, a chimera of several mammals that was 'discovered' in 1663. “The horn, together with the head, several ribs, dorsal vertebrae and bones were brought to the town's serene abbess", Leibniz confides, evidently deeming the words of this particular local eyewitness reliable. Nonetheless, he takes on board the field examples described by Steno that show how a sequence of strata revealed something of Earth's history. Scientific narrative was only a step away.
When considering the origin of minerals, Leibniz has an intuitive sense that a kind of natural cookery is involved: "One is thus inclined to suspect that nature, using volcanoes as furnaces and mountains as alembics, has accomplished in her mighty works what we play at with our little examples [in laboratories]." That the furnaces of the 'chymist' might simulate Earth's processes is a hope that still drives research into petrology and geochemistry today.

Why then did Leibniz's shrewd observations fail to move geology significantly towards becoming a mature science? For all its insights, Protogaea does not seem to a modern geologist like the natural ancestor of Lyell's Principles of Geology. The missing ingredient is an awareness of geological time. Leibniz did not place the biblical timescale centrally in his science - he was actually very restrained in invoking the Creator. A short timescale was simply a given, so widely accepted that he did not have to restate it. Even Leibniz's evident awareness of events such as major incursions of the sea over what is now dry land did not challenge his view. Geology without time is rather like chemistry without elements: a collection of plausible narratives is possible; a rational basis for predictive science is not.

More mundanely, it was also difficult to travel in the eighteenth century. Leibniz had to rely on the observations of others simply because wide-scale fieldwork was almost impossible. Armchair speculation was inevitable, despite Leibniz's careful affirmation of his own observations. The true complexity of Earth's history did not begin to be exposed until French geologists started work in the Auvergne and the Paris basin, and until James Hutton developed his theory of deep geological time in Scotland. The improvement of roads and canals, and then the advent of railways, allowed for different local geological narratives to be stitched together. Earth science has subsequently developed to recognize our planet as an interconnected system that has evolved over billions of years. Leibniz's world is an incomplete patchwork of local stories.

Richard Fortey is a research associate at the Natural History Museum, Cromwell Road, London SW7 5BD, UK. He is author of The Earth: An Intimate History.

e-mail:r.fortey@nhm.ac.uk 